\title{
KAJIAN SEMIOTIKA ORNAMEN DAN RAGAM HIAS AUSTRONESIA PADA ARSITEKTUR TRADISIONAL NUSANTARA ${ }^{1}$ Study of Semiotics of Austronesian Ornament and Decorative Arts in Nusantara Traditional Architecture
}

\author{
Doni Fireza dan Adli Nadia \\ Program Studi Arsitektur, Universitas Agung Podomoro \\ APL Tower Lt. 5, Jalan Letjen S. Parman Kav 28, Jakarta Barat \\ E-mail: doni.fireza@podomorouniversity.ac.id \\ Naskah diterima: 20 Maret 2020 - Revisi terakhir: 10 April 2020 \\ Disetujui terbit: 15 November 2020 - Tersedia secara online: 30 November 2020
}

\begin{abstract}
Ornament and decorative arts of Nusantara traditional architecture are works of art originating from Austronesian culture. Besides functioning as decoration, it is also as a bearer of meaningful traditional messages in a sign system. How its existence and development as a visual language from the point of view of semiotics is interesting to study. This paper examines the relationships between signs in the system of sign contained in the ornament and decorative arts of Nusantara traditional architecture. The discussion includes; (1) analysis of the triadic relation from sign systems of the ornaments and decorative arts, (2) analysis of the pragmatic relations of the visual works and the way they work in the system of sign as visual language, and (3) diachronic analysis of the form and function of the ornaments and decorative arts in the system of sign. The result obtained is a form of appreciation of the art tradition which revealed the existence of the Nusantara traditional architectural ornament and decorative art as a sign of cultural evolution and the media for conveying messages from traditional customs.
\end{abstract}

Keywords: semiotics, ornament and decorative arts, Austronesia, Nusantara architecture

\begin{abstract}
Abstrak
Ornamen dan ragam hias arsitektur tradisional Nusantara adalah karya rupa yang berasal dari kebudayaan Austronesia. Selain berfungsi sebagai hiasan, benda tersebut juga sebagai pembawa pesan adat yang penuh makna dalam sebuah sistem tanda. Bagaimana eksistensi dan perkembangannya sebagai bahasa rupa dari sudut pandang ilmu tanda atau semiotika menarik untuk dikaji. Tulisan ini mengkaji relasi-relasi antartanda pada sistem tanda yang terdapat pada ornamen dan ragam hias arsitektur tradisional Nusantara. Pembahasan meliputi (1) analisis relasi triadik sistem tanda dari karya rupa, (2) analisis relasi pragmatis karya rupa dan cara bekerjanya dalam sistem tanda sebagai bahasa rupa, dan (3) analisis diakronik dari wujud dan fungsi karya rupa sebagai sistem tanda. Hasil yang didapat adalah apresiasi tradisi karya rupa berupa pengungkapan eksistensi dari ornamen/ragam hias arsitektur adat Nusantara sebagai sistem tanda perkembangan kebudayaan dan media penyampaian makna dari adat istiadat.
\end{abstract}

Kata kunci: semiotika, ornamen dan ragam hias, Austronesia, arsitektur Nusantara

1 Tulisan ini dipresentasikan pada Seminar Nasional Balai Arkeologi Jawa Barat "Indonesia Rumah Besar Austronesia dari Masa Prasejarah Hingga Kini” Mason Pine Bandung, 19_21 November 2019. 


\section{PENDAHULUAN}

Karya rupa pada kebudayaan Austronesia sudah muncul dalam penggunaan motif-motif hiasan yang ada pada perkakas gerabah yang digunakan peradaban ini pada ribuan tahun yang lalu. Ragam hias ini kemudian berkembang pada sekitar 500 SM setelah introduksi tradisi logam besi-perunggu yang dibawa oleh kebudayaan Dong Son (van Heekeren, 1958, pp. 92-98; Solheim II, 1990, p. 23; Bellwood, 2007, pp. 277283). Penggunaan karya rupa ini ditandai dengan banyaknya ditemukan artefak perkakas lepasan yang berhiaskan motif ragam hias ini, baik perkakas gerabah maupun besi-perunggu.

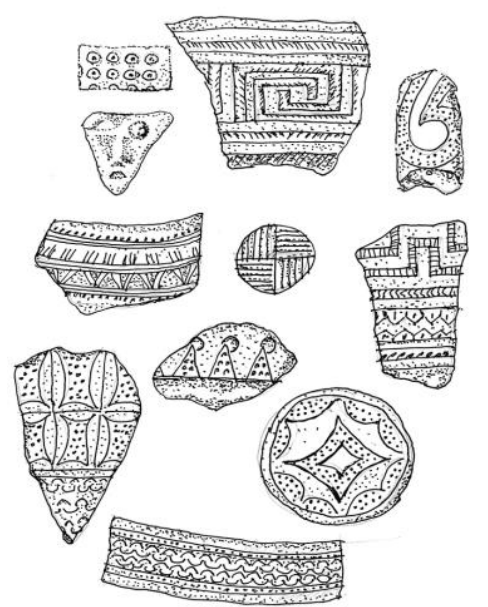

Gambar 1. Pola-Pola Ragam Hias pada Artifak Tembikar dari Budaya Austronesia dari Kalumpang, Sulawesi Tengah

Terdapat pola geometrik dan yang menyerupai wajah manusia menurut van Heekeren, 1972

(Sumber: Digambar ulang dari Bellwood, 2007).

Studi mengenai karya rupa ragam hias dan ornamen dari budaya Austronesia sudah banyak dilakukan. Studi-studi tersebut menyatakan pengelompokan motif karya rupa (geometrik dan figuratif), gaya desain (skematik dan realistik), dan pola-pola desain (deformasi atau stilisasi), interpretasi dari pola dan motif ragam hias tersebut terkait dengan masa kebudayaannya, serta di antaranya juga membahas kesamaan pola dan motif antarartifak yang berasal dari berbagai macam situs, termasuk juga studi tentang teknik pembuatan karya rupa tersebut dengan cara teknologi cor logam dengan cetakan dari lilin dan tanah liat (Solheim II, 1990, p. 24; Bellwood, 2007, p. 271; Chiou-Peng, 2008, pp. 36-38; Wijaya, 2013, pp. 214-219; Leihitu \& Permana, 2019, pp. 222-225). Selain berfungsi sebagai hiasan, karya rupa ini juga berfungsi sebagai penanda dan terkait kegiatan ritual. Sebagai penanda, karya rupa ini muncul sebagai tanda kemajuan kebudayaan, seperti di bidang pertanian dan peternakan dengan munculnya pola-pola hias di nekara, sebagai contoh orang yang bekerja dengan lumpang dan alu serta adanya lumbung dan binatang ternak babi, ayam, anjing, dan tikus (Thomas, 2011, p. 3; Jusoh, 2016, pp. 8-9). Karya rupa ini juga ditempatkan pada benda-benda yang berhubungan dengan kegiatan ritual kepercayaan sehingga mempunyai interpretasi makna yang terkait dengan pemujaan (Yudoseputro, 2008, pp. 9-12; Mallabasa \& Subiantoro, 2018, pp. 4-5). Kepercayaan mereka juga menganggap 
bahwa arwah orang yang sudah meninggal masih berhubungan dengan manusia lewat dimensi lain. Ini kemudian menjadi inspirasi ide dan ekspresi dari karya seni rupa, seperti motif mimesis wajah manusia, pola manusia naik kapal panjang (kapal arwah) dengan bertutup kepala berhias bulu burung yang juga menunjukkan kemampuan mereka dalam berpindah-pindah pulau (Chiou-Peng, 2008, pp. 36-38; Thomas, 2011, pp. 6-7; Wijaya, 2013, pp. 218-219). Motif manusia dengan pola berbaris yang memegang semacam senjata dinterpretasikan sebagai kegiatan parade pejuang yang sedang baris-berbaris dalam kegiatan terkait ritual (Jusoh, 2016, p. 12). Kepercayaan pada kekuatan gaib atau magisme memang secara fungsional sering muncul pada ungkapan karya seni rupa masyarakat prasejarah (Yudoseputro, 2008, pp. 10-11). Nilai sakral menjadi ciri utama dari karya seni rupa prasejarah di samping nilai sosial berdasarkan fungsinya sebagai media komunikasi nilai.

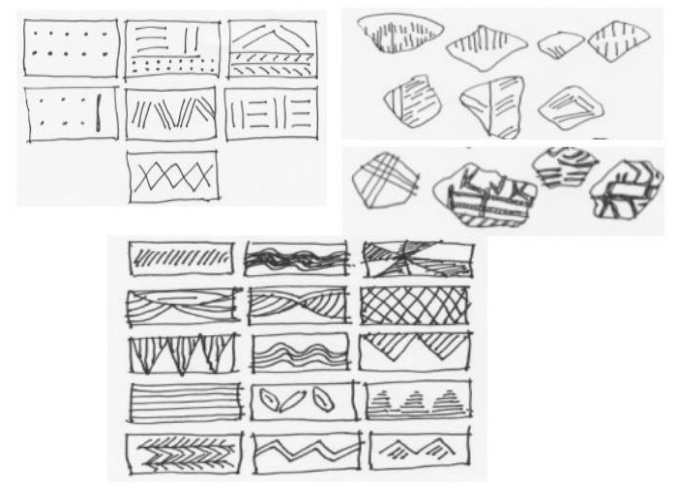

Gambar 2. Beberapa Contoh Sketsa Salinan dari Pola Ragam Hias Austronesia pada Artifak Tembikar yang Ditemukan di Anyer (Kiri Atas), Gunung Wongko (Kanan Atas), dan Gilimanuk (Bawah) (Sumber: Digambar Ulang dari Simanjuntak, RMB, 2009).

Dalam sejarah perkembangan arsitektur Nusantara, dinyatakan bahwa salah satu bentuk dasar dari rumah adat Nusantara adalah turunan langsung dari rumah orang Austronesia yang juga terlihat pada gambaran artifak perunggu, relief candi, dan naskah-naskah lama (Fox, 2006b, pp. 1-19; Waterson, 2006, pp. 227-236; Bellwood, 2007, p. 150). Ragam hias dan ornamen merupakan bagian dari karya arsitektur tradisional Nusantara yang berkembang seiring dengan perkembangan karya rupa seni ragam hias Austronesia yang menjadi bagian dari kebudayaan Nusantara. Sebagai bagian dari budaya seni rupa, karya rupa Austronesia ini berkembang beratus tahun kemudian sebagai ragam hias dari arsitektur tradisional Nusantara, bercampur dengan pengaruh agama dan budaya asing (India, China, Arab, Barat) yang membentuk kebudayaan hibrid (Fox, 2006a, pp. 231-236; Maziyah et al., 2016, pp. 25-26).

Studi tentang eksistensi dan perkembangan penggunaan ornamen dan ragam hias dari karya rupa Austronesia sebagai elemen dari arsitektur tradisional Nusantara dengan pendekatan ilmu tanda atau semiotika relatif belum dilakukan. Eksistensi ragam hias dan ornamen Austronesia yang muncul sebagai elemen arsitektur tradisional selain 
sebagai karya rupa dapat dilihat juga sebagai bagian dari sistem tanda dan memiliki relasi di antaranya sebagai bagian dari sistem tanda. Sistem tanda yang ada antara lain sebagai elemen fungsional dekoratif, sebagai penanda kemajuan peradaban, dan juga sebagai bahasa rupa penyampai makna dan gagasan yang berasal dari adat istiadat. Untuk membaca perkembangan fungsi-fungsi dari ornamen dan ragam hias tersebut, digunakan ilmu tanda atau semiotika sebagai pengungkap relasi-relasi di antara fungsi ornamentasi dan fungsi komunikasi budaya.
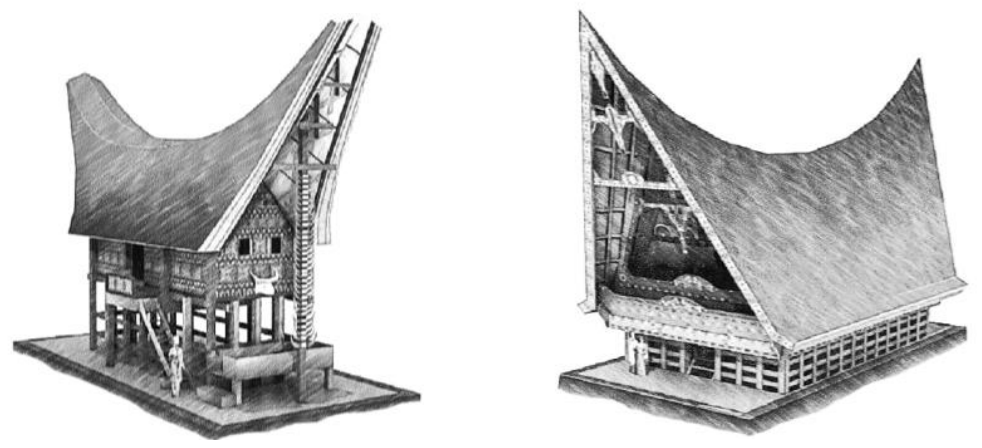

Gambar 3. Contoh Rumah Adat di Nusantara yang Mempunyai Kemiripan Bentuk dengan Rumah Austronesia

Rumah Adat Tongkonan Toraja (Kiri) dan Batak Toba (Kanan) (Sumber: Disunting dari Sumardiono, 2010 dan Xperia-Newz, 2015).

Dalam semiotika, ornamen dan ragam hias adalah karya rupa dari kebudayaan dan merupakan bahasa rupa yang dapat diamati sebagai sistem tanda yang mempunyai fungsi dan makna. Tulisan ini mengungkap bagaimana eksistensi karya rupa arsitektur tradisional Nusantara yang bersumber dari kebudayaan Austronesia sebagai sistem tanda dalam pendekatan semiotika arsitektur. Bagaimana mengurai fungsi tanda-tanda dan relasi-relasi antartanda yang terjadi dalam sistem tanda karya rupa ini juga diungkapkan dalam pendekatan ini. Proses pengungkapan ini bertujuan untuk mengapresiasi dan melestarikan tradisi karya rupa tradisional Nusantara sebagai bahasa rupa pembawa makna adat.

Semiotika arsitektur atau kajian tentang sistem tanda pada arsitektur adalah suatu kajian yang meliputi konsep mental, fungsi, desain, bentuk, eksistensi fisik, makna, dan pesan yang dibawa oleh setiap elemen arsitektur pada karya arsitektur tersebut (Eco, 1980, pp. 15-24; Jencks, 1980, pp. 74-82; Putra \& Ekomadyo, 2015, pp. 2-3). Dengan demikian, semiotika yang tepat untuk membahas karya arsitektur adalah semiotika modern yang dicetuskan oleh Charles Peirce. Peirce menyatakan bahwa terdapat suatu relasi yang sifatnya segitiga antara tanda (sign) atau objek yang dipahami berkarakter suatu tanda, representament atau objek atau benda yang dikenal sebagai pembawa tanda tersebut (signifier), dan personal yang memaknai tanda tersebut (interpretant/signified) (Eco, 1980, pp. 14-17; Hoed, 2014, pp. 8-10). Model relasi segitiga ini dikenal dengan model relasi triadik dalam sebuah sistem tanda.

Pembawa tanda/penanda (signifier) yang berwujud dan akan memiliki suatu citra yang mewakili objek tanda berelasi dengan petanda (signified atau interpretant), 
yaitu bagaimana tanda tersebut dimaknai oleh seseorang lewat suatu konsep mental. Apabila digambarkan dalam sebuah bentuk relasi, model relasi triadik dari semiotika tersebut dapat dimunculkan sebagai berikut.

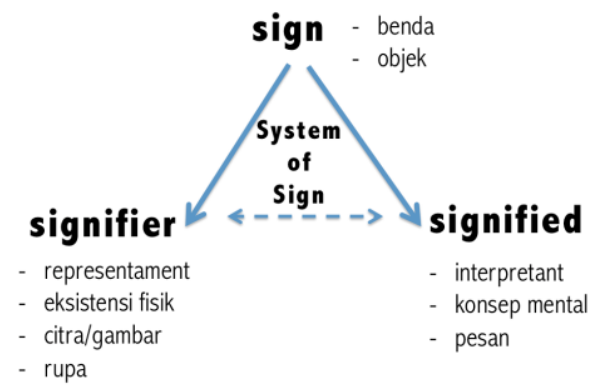

Gambar 4. Interpretasi Penulis akan Model Relasi Triadik Sistem Tanda yang

Dikembangkan dari Semiotika Versi Peirce.

Dalam pandangan semiotika, ide dari pemikiran manusia ini adalah sebuah tanda yang dihadirkan oleh karya arsitektur yang dapat dilihat sebagai teks, sedangkan makna yang dibawa tanda tersebut berperan sebagai konsep yang dibawa oleh desain arsitektur. Sistem tanda yang merupakan naungan relasi triadik ini adalah konteks tempat desain arsitektur sebagai media komunikasi ide dan kebudayaan. Memahami relasi antara konsep mental suatu karya arsitektur, bentukan desainnya, dan ide budaya yang dibawanya adalah inti dari semiotika arsitektur. Kritikus arsitektur Charles Jencks kemudian memunculkan suatu relasi triadik dari semiotika yang tetap berkaitan dengan relasi triadik Peirce di atas. Dalam sistem tanda ini, Jencks mengembangkan terminologi (1) simbol (symbol) sebagai bentuk lain dari penanda dalam sistem tanda pada arsitektur, (2) pikiran (thought) sebagai bentuk lain dari konsep mental, dan (3) rujukan (referent) sebagai bentuk lain atau acuan dari eksistensi bentuk/desain, yang langsung berkaitan dengan fungsi utama dari arsitektur tersebut (Jencks, 1980, pp. 8082).

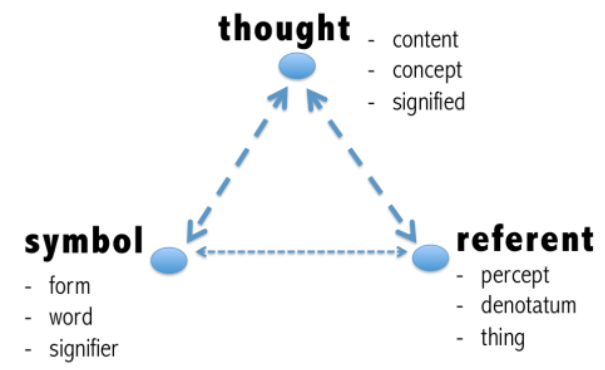

Gambar 5. Relasi Triadik dalam Sistem Tanda pada Arsitektur menurut Charles Jencks. (Sumber: Jencks, 1980).

Charles Peirce, sebagai pakar semiotika linguistik menyatakan bahwa ada tiga hubungan pragmatis yang terkait dengan tanda (Sachari, 2005, pp. 65-66; Hoed, 2014, pp. 8-10), yaitu (1) ikon, menyatakan hubungan tanda dengan acuannya berupa hubungan kemiripan, (2) indeks, menyatakan hubungan yang bersifat sebab akibat atau kedekatan eksistensial, dan (3) simbol, menyatakan yaitu hubungan yang terbentuk oleh konvensi sosial dan bersifat kultural. Setiap tanda dapat mengandung hubungan salah 
satu atau dua di antara tiga di atas, tetapi juga dapat berhubungan dengan ketiganya. Tiga hubungan pragmatis ini kemudian juga berhubungan dengan relasi suatu tanda dengan tanda lainnya yang terbagi menjadi tiga golongan cara bekerjanya, yaitu (1) sintaksis, menyatakan relasi antartanda yang menunjukkan kesamaan dan kerja sama, (2) pragmatik, menyatakan relasi antartanda yang berhubungan dengan fungsi dan pemakainya, dan (3) semantik, menyatakan relasi antartanda yang berhubungan dengan pemaknaan, denotasi, dan penafsirannya (Sachari, 2005, p. 66; Hoed, 2014, pp. 23-25). Ornamen dan ragam hias dalam arsitektur dalam sistem tanda adalah suatu bentuk fisik yang bereksistensi lewat citra rupa dan desain serta memiliki konsep dan pesan budaya. Setiap elemen dalam sistem tanda mempunyai relasi dalam cara bekerjanya. Dengan demikian, semiotika menjadi relevan untuk menjelaskan relasi yang terjadi pada satu sistem tanda tersebut.

Umberto Eco mengkaitkan fungsi tanda-tanda dalam arsitektur dan elemenelemennya sebagai media komunikasi suatu ide. Tanda dalam arsitektur adalah suatu media yang membawa makna denotatif, yaitu tingkat pertama dari tatanan pertandaan yang fungsi utama tanda sebagai bentuk eksistensial dalam karya rupa arsitektur (Eco, 1980, pp. 20-23; Kemas, 2017, pp. 7-10). Karena makna denotatif ini dapat berkembang lepas dari fungsi utama/aslinya, dalam relasinya, bentuk/penanda denotatif ini menjadi faktor yang memengaruhi desain. Dengan demikian, suatu makna denotatif dari suatu tanda dapat terbagi menjadi dua fungsi, yaitu fungsi utama dan fungsi pengembangan, yang keduanya bekerja sama beriringan (contextual juxtaposition) untuk dapat dipahami isi konsep yang akan diwakilinya.

Selain denotatif, pada tanda terdapat makna konotatif, yaitu makna yang terkandung/implisit yang berkaitan dengan konsep kulturalnya. Hal itu dibaca dalam denotasi dari penggunaan utama tanpa mengurangi tingkat kepentingan fungsi utamanya. Makna konotasi juga berkaitan dengan hubungan tanda sebagai simbol yang mengomunikasikan bagaimana fungsi sosial dari simbolisme yang ada pada objek. Makna konotasi sebagai simbol pada fungsi sosial ini terkadang lebih penting daripada fungsi utamanya, yang dikandung oleh denotasi seiring dengan perkembangan historis penggunannya karena juga sebagai alat untuk mengekspresikan emosi, suasana hati, pikiran tertentu, dan sebagainya (Jencks, 1980, pp. 80-81; Macbean, 2013, pp. 8-10).

Oleh karena itu, peran konotatif yang dimunculkan oleh fungsi tambahan tadi justru lebih penting dalam mengomunikasikan ide-ide budaya. Dengan demikian, terdapat nilai-nilai denotatum dan konotatum dari setiap ornamen dan ragam hias pada setiap karya arsitektur tersebut karena akan selalu ada dimensi makna, yaitu makna yang disampaikan oleh pembuatnya dan makna yang dipahami oleh penikmatnya dalam suatu rentang waktu (Jencks, 1980, pp. 80-82; Sachari, 2005, p. 70; Vine, 2008, pp. 3536; Macbean, 2013, pp. 5-6; Hoed, 2014, pp. 77-80; Kharisma et al., 2015, pp. 3-4).

Uraian tentang semiotika, relasi sistem tanda, hubungan antartanda, perkembangan wujud dan fungsi, dan pemaknaan suatu tanda dapat diturunkan pada suatu model semiotika yang dapat digunakan untuk menganalisis semiotika bahasa rupa. 

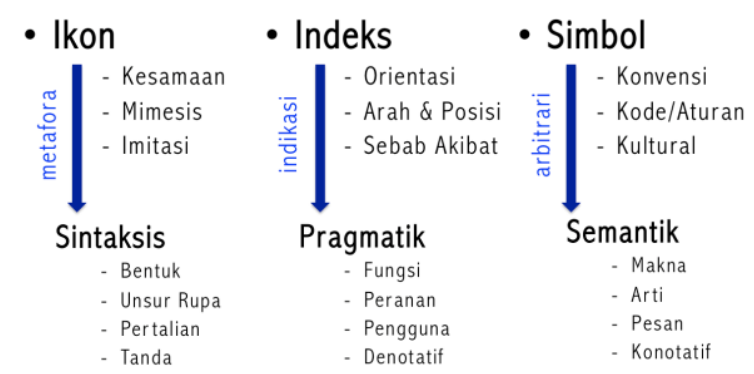

Gambar 6. Interpretasi Penulis akan Relasi Pragmatis dan Cara Bekerjanya dari Karya Rupa/Arsitektur dalam Sistem Tanda.

Sistem tanda dalam arsitektur, apabila dilihat pada model di Gambar 6, akan bersifat gabungan. Tanda dalam arsitektur akan dapat muncul sebagai ikon, indeks, dan simbol secara bersamaan, hanya mempunyai satu tanda yang dominan.

Ornamen dan ragam hias pada arsitektur tradisional Nusantara secara garis besar dapat dikelompokkan menjadi beberapa kelompok motif, yaitu motif geometrik (bentuk-bentuk dasar dan tumbuhan) dan motif figuratif, seperti mimesis hewan dan mimesis manusia (Solheim II, 1990, pp. 24-28; Yudoseputro, 2008, pp. 9-10; Aisyah, 2018, pp. 401-402; Leihitu \& Permana, 2019, p. 225). Motif-motif ini bermunculan dalam pola, gaya, dan nama yang bermacam-macam dan ditempatkan pada beberapa posisi tertentu pada rumah adat. Hubungan antara motif, pola, gaya, penamaan, dan warna dengan fungsi/peranan dalam arsitektur, serta makna dan pesan yang akan disampaikan merupakan relasi antartanda yang dapat ditelaah dengan menggunakan kajian sistem tanda atau semiotika.

Tulisan ini merupakan kajian pustaka mengenai penggunaan sudut pandang semiotika dalam kajian arsitektur. Tulisan ini bertujuan untuk mengetahui gambaran eksistensi akan tradisi bahasa rupa yang menunjukkan suatu relasi sistem tanda antara bentuk/desain, fungsi, dan pemaknaan sebagai media komunikasi ide dan konsep adat istiadat dan budaya. Metodologi yang dipakai adalah metodologi kualitatif dengan mengkaji semiotika bahasa rupa dari ornamen dan ragam hias Austronesia pada arsitektur tradisional. Pembahasan dilakukan dengan analisis relasi triadik pada sistem tanda dari suatu karya rupa dalam konteks adat istiadatnya. Berikutnya kajian dilakukan dengan menganalisis relasi pragmatis dari karya rupa dengan cara bekerja dalam sistem tanda yang dilakukan dengan mengurai beberapa sampel ragam hias/ornamen yang terdapat pada artifak lepasan Austronesia dan pada rumah adat Nusantara. Dilakukan juga analisis perkembangan historis/diakronik dari wujud dan fungsi desain untuk menggambarkan perkembangannya sebagai bahasa rupa.

\section{HASIL DAN PEMBAHASAN}

Dalam kajian ini dilakukan analisis dari relasi triadik yang berupa hubungan antara sifat-sifat karya rupa tersebut sebagai tanda/rujukan sebagai perwujudan fisik, fungsinya sebagai penanda/simbol/visualisasi/desain, dan dengan sifatnya sebagai petanda/pikiran/pembawa konsep mental/pesan. Relasi ini dibaca dalam konteks 
kebudayaan sebagai media komunikasi ide dan nilai adat. Dengan demikian, dapat dimunculkan suatu model relasi dari sistem tanda sebagai berikut.

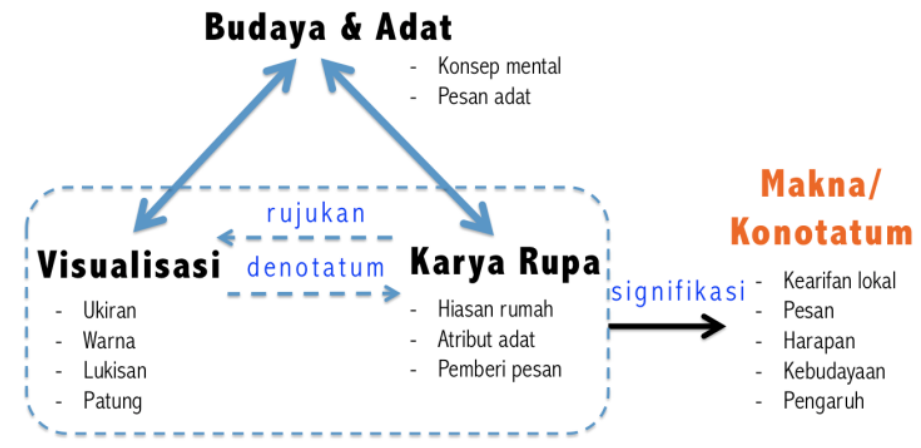

Gambar 7. Model Semiotika Bahasa Rupa dari Ornamen/Ragam Hias Austronesia-Rumah Adat Nusantara.

Berdasarkan model tersebut, dapat diuraikan bahwa karya rupa, jika dipandang sebagai sistem tanda, mempunyai hubungan-hubungan sebagai berikut.

- Sebagai penanda/signifier, karya rupa mempunyai eksistensi fisik yang diwujudkan oleh visualisasi berupa ukiran, lukisan, atau skulptur yang mempunyai unsur-unsur desain, seperti bentuk, warna, raut, komposisi, dan sebagainya.

- Sebagai rujukan/referent, karya rupa merupakan acuan dari sebuah visualisasi yang diserap oleh penikmatnya dan mempunyai nilai denotatumnya, baik sebagai hiasan pada elemen-elemen rumah adat maupun sebagai atribut dari kegiatan adat.

- Kedua sifat di atas adalah hasil pikiran dan konsep mental yang diturunkan oleh budaya yang bekerja di pikiran penikmat sebagai petanda/signified sekaligus sebagai media pembawa pesan adat.

- Relasi ketiganya akan memunculkan suatu kepentingan yang lebih utama dalam eksistensinya, yaitu nilai konotatum yang berupa kandungan makna yang tersirat berupa harapan, pencapaian, kearifan lokal, dan lain-lain yang akan dikomunikasikan kepada penikmatnya sebagai sebuah ekspresi budaya.

Analisis akan relasi pragmatis dari suatu ornamen dan ragam hias dengan cara bekerjanya dalam sistem tanda sebagai bahasa rupa dari berbagai sampel dari era Austronesia dan arsitektur tradisional Nusantara dapat dilihat pada tabel-tabel berikut.

Tabel 1. Analisa Semiotika Bahasa Rupa Austronesia

\begin{tabular}{|c|c|c|c|c|}
\hline \multicolumn{3}{|c|}{ Ikon dan Sintaksis } & \multicolumn{2}{|c|}{ Indeks dan Pragmatik } \\
\hline Desain & Posisi (Asal) & Bentuk/Nama & Denotatif Utama & Denotatif Pengembangan \\
\hline \multicolumn{5}{|l|}{ Motif Geometrik } \\
\hline $\begin{array}{c}\text { (Le) } \\
\text { Permanitu \& }\end{array}$ & $\begin{array}{c}\text { Lukisan Gua } \\
\text { (Papua Barat) }\end{array}$ & $\begin{array}{l}\text { Matahari/ } \\
\text { Cakram }\end{array}$ & $\begin{array}{l}\text { - Hiasan, estetika, } \\
\text { - Karya seni rupa } \\
\text { - Kalender musiman } \\
\text { - Media upacara keagamaan }\end{array}$ & $\begin{array}{l}\text { - Makna sakral } \\
\text { - Nilai status sosial } \\
\text { - Atribut kekuasaan } \\
\text { - Cita rasa masyarakat }\end{array}$ \\
\hline & Nekara (Semarang) & $\begin{array}{l}\text { Matahari/ } \\
\text { Bintang }\end{array}$ & & \\
\hline (Heekeren, 1958) & & & & \\
\hline
\end{tabular}




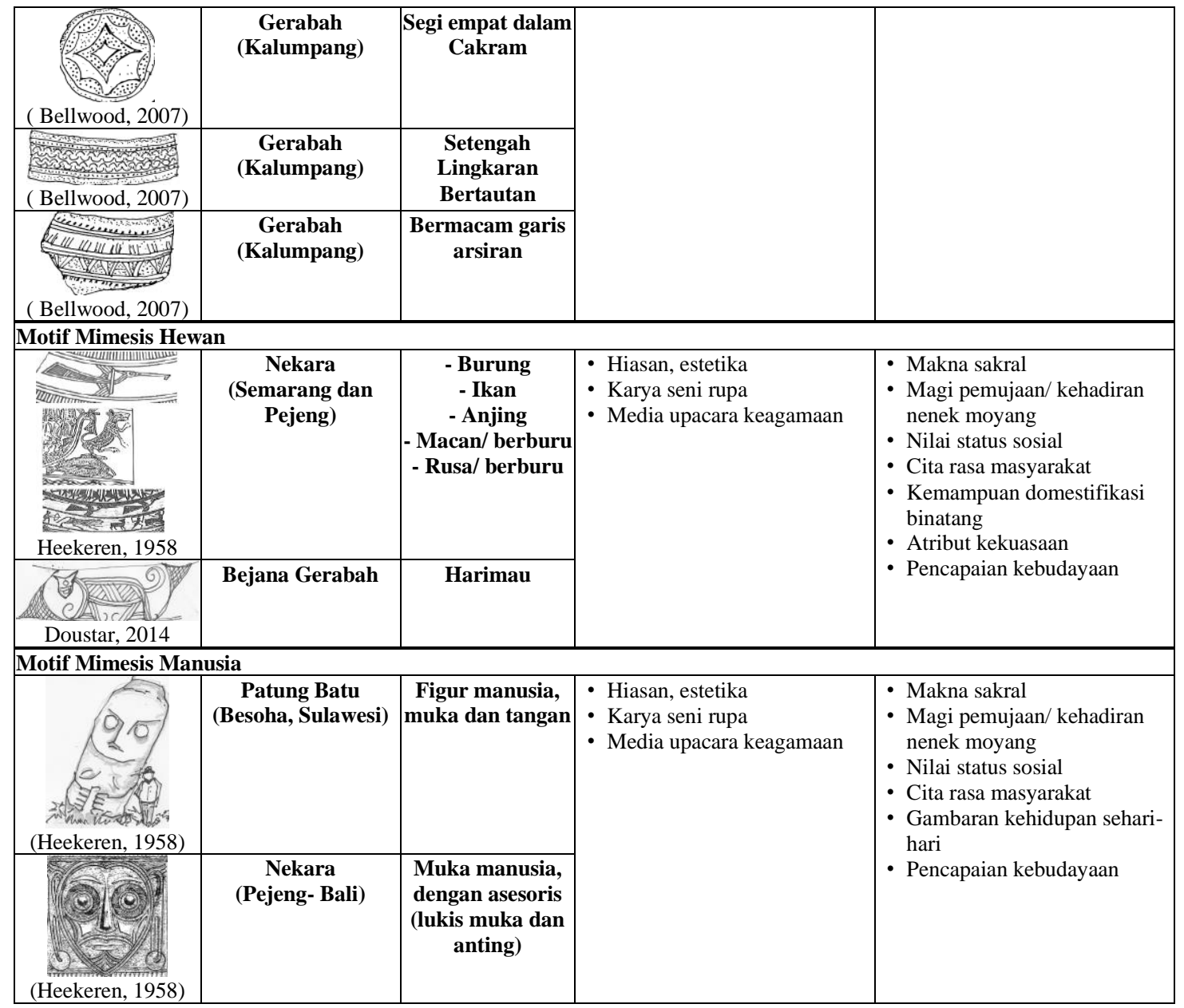

(Sumber: van Heekeren, 1958; Solheim II, 1990; Groves, 2006; Chiou-Peng, 2008; Yudoseputro, 2008; Wijaya, 2013; Jusoh, 2016; Mallabasa \& Subiantoro, 2018; Leihitu \& Permana, 2019).

Tabel 2. Analisa Semiotika Bahasa Rupa Motif Geometrik Era Arsitektur Nusantara

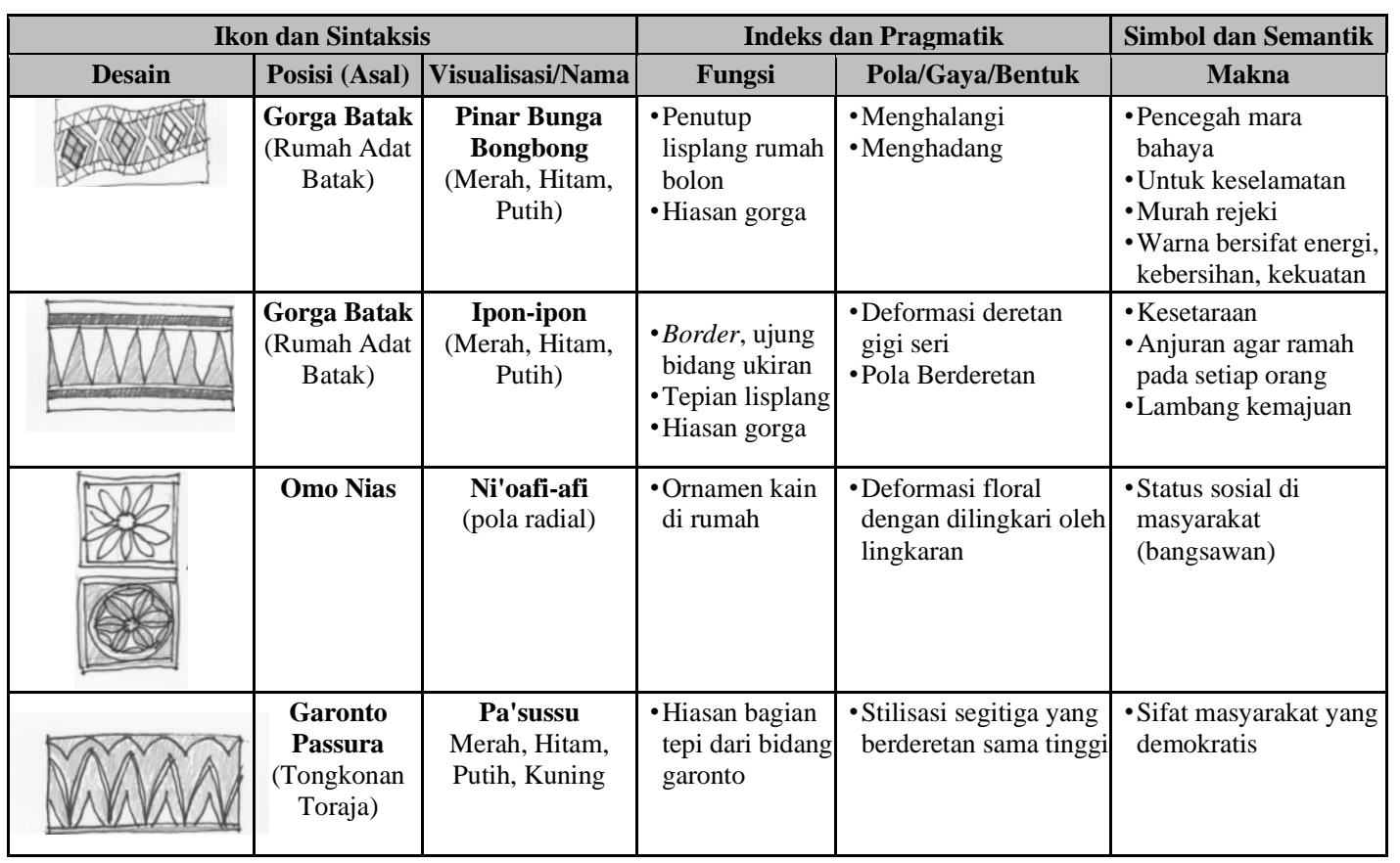




\begin{tabular}{|c|c|c|c|c|c|}
\hline NMDD & $\begin{array}{l}\text { Garonto } \\
\text { Passura } \\
\text { (Tongkonan } \\
\text { Toraja) }\end{array}$ & $\begin{array}{l}\text { Pa'barre Allo } \\
\text { Merah, Hitam, } \\
\text { Putih, Kuning }\end{array}$ & $\begin{array}{l}\cdot \text { Ornamen sopi- } \\
\text { sopi rumah } \\
\text { - Point of } \\
\text { interest }\end{array}$ & $\begin{array}{l}\text { - Stilisasi realistik } \\
\text { lingkaran dengan } \\
\text { ornamen keliling yang } \\
\text { memusat pada satu } \\
\text { titik pusat }\end{array}$ & $\begin{array}{l}\text { • Kepercayaan bahwa } \\
\text { Tuhan YME adalah } \\
\text { sumber kehidupan }\end{array}$ \\
\hline$\sqrt{13 \sqrt{5}}$ & $\begin{array}{c}\text { Rumah } \\
\text { Bagonjong } \\
\text { Minangkabau }\end{array}$ & \begin{tabular}{|c|} 
Itiak Pulang \\
Patang \\
Bermacam-macam \\
dan selang-seling
\end{tabular} & $\begin{array}{l}\cdot \text { Ornamen } \\
\text { tepian bidang } \\
\text { ukiran dinding }\end{array}$ & $\begin{array}{l}\text { - Deformasi skematik } \\
\text { bentuk badan itik } \\
\text { yang jalan berbaris } \\
\text { berderetan }\end{array}$ & $\begin{array}{l}\text { - Kehidupan mengejar } \\
\text { keselarasan } \\
\text {-Anak perempuan } \\
\text { harus pulang sebelum } \\
\text { gelap } \\
\text { - Menjaga sistem } \\
\text { kekerabatan } \\
\end{array}$ \\
\hline & Omo Nias & $\begin{array}{c}\text { Ni'osolafiga } \\
\text { Ni'ohatuyo } \\
\text { Merah, Hitam, } \\
\text { Emas }\end{array}$ & $\begin{array}{l}\cdot \text { Ornamen pola } \\
\text { di rumah. } \\
\text { - Hiasan di kain } \\
\text { tenun }\end{array}$ & $\begin{array}{l}\text { - Deformasi skematik } \\
\text { segitiga ujung tombak } \\
\text { berderet } \\
\text {-Segiempat berbentuk } \\
\text { berlian }\end{array}$ & $\begin{array}{l}\text {-Persatuan dan gotong } \\
\text { royong } \\
\text {-Jiwa kepahlawanan } \\
\text {-Status sosial } \\
\text { kebangsawanan }\end{array}$ \\
\hline (c) (1) & $\begin{array}{c}\text { Rumah } \\
\text { Lamin Dayak }\end{array}$ & $\begin{array}{l}\text { Motif Pakis } \\
\text { Hitam, Putih, } \\
\text { Kuning }\end{array}$ & $\begin{array}{l}\text {-Hiasan dinding } \\
\text { luar rumah }\end{array}$ & $\begin{array}{l}\text { - Stilisasi skematik } \\
\text { bentuk pakis yang } \\
\text { dibentuk lengkung- } \\
\text { lengkung simetris }\end{array}$ & $\begin{array}{l}\text { - Penolak Bala } \\
\text { - Penangkal teluh/sihir }\end{array}$ \\
\hline
\end{tabular}

(Sumber: Sipayung \& Lingga, 1995; Lullulangi \& Sampebua', 2007; Viaro, 2008; Prasetya \& Adi, 2011; Prasetyo, 2014; Amzy, 2017; Aisyah, 2018; Hidayat, 2018; Khairuzzaky, 2018).

Tabel 3. Analisa Semiotika Bahasa Rupa Motif Mimesis Hewan Era Arsitektur Nusantara

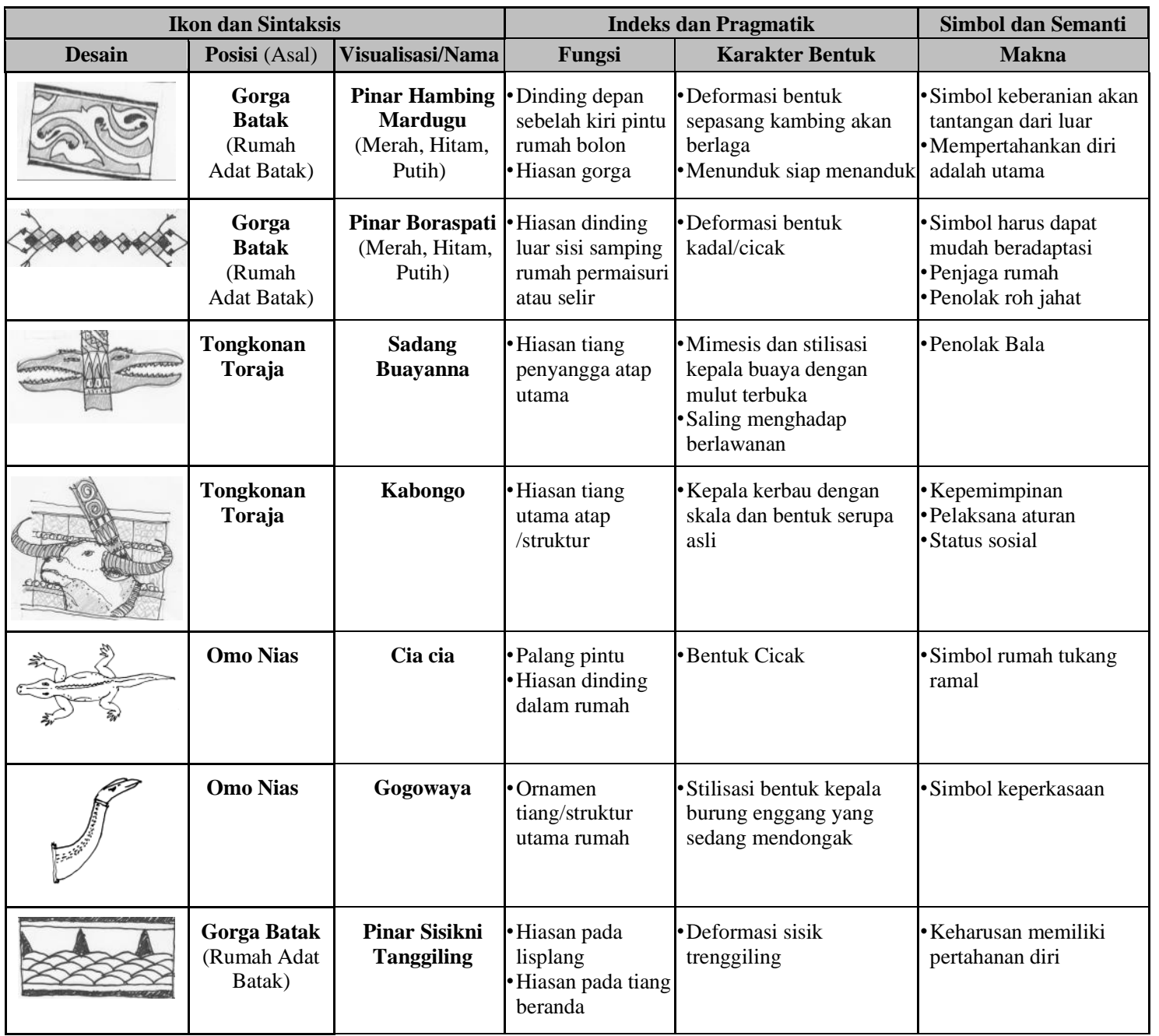




\begin{tabular}{|c|c|c|l|l|l|}
\hline $\begin{array}{c}\text { Rumah } \\
\text { Lamin } \\
\text { Dayak }\end{array}$ & $\begin{array}{c}\text { Mahatala/ } \\
\text { Pohotala }\end{array}$ & $\begin{array}{l}\text {-Ornamen dinding } \\
\text { Ornamen } \\
\text { bubungan atap }\end{array}$ & $\begin{array}{l}\cdot \text { Stilisasi dari Burung } \\
\text { Enggang }\end{array}$ & $\begin{array}{l}\cdot \text { Jelmaan sosok sakti } \\
\cdot \text { Kemuliaan dan } \\
\text { kebesaran } \\
\cdot \text { Lambang kesetiaan }\end{array}$ \\
\hline
\end{tabular}

(Sumber: Sipayung \& Lingga, 1995; Lullulangi \& Sampebua', 2007; Viaro, 2008; Prasetya \& Adi, 2011; Mayasari et al., 2014; Prasetyo, 2014; Putra \& Ekomadyo, 2015; Amzy, 2017; Marlina, 2017; Hidayat, 2018).

Tabel 4. Analisa Semiotika Bahasa Rupa Motif Mimesis Manusia Era Arsitektur Nusantara

\begin{tabular}{|c|c|c|c|c|c|}
\hline \multicolumn{3}{|c|}{ Ikon (Sintaksis) } & \multicolumn{2}{|c|}{ Indeks (Pragmatik) } & Simbol (Semantik) \\
\hline Desain & Posisi (Asal) & Visualisasi/Nama & Fungsi & Karakter Bentuk & Makna \\
\hline 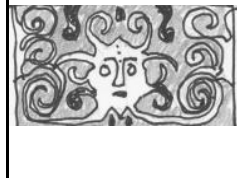 & $\begin{array}{l}\text { Rumah } \\
\text { Lamin } \\
\text { Dayak }\end{array}$ & $\begin{array}{l}\text { Udo, Kelunan } \\
\text { (kuning, putih, } \\
\text { htam, merah) }\end{array}$ & \begin{tabular}{|l|} 
- Hiasan dinding \\
depan rumah \\
Lamin \\
- Sarana pemujaan \\
leluhur
\end{tabular} & $\begin{array}{l}\text { - Skematik/Deformatif } \\
\text { muka manusia }\end{array}$ & $\begin{array}{l}\text { - Penolak bala } \\
\text { - Menjaga rumah } \\
\text { - Perwujudan nenek moyang }\end{array}$ \\
\hline 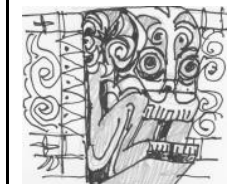 & $\begin{array}{c}\text { Gorga } \\
\text { Batak } \\
\text { (Rumah } \\
\text { Adat Batak) }\end{array}$ & $\begin{array}{l}\text { Gorga Singa- } \\
\text { singa } \\
\text { (Merah, Hitam, } \\
\text { Putih) }\end{array}$ & \begin{tabular}{|l|} 
Patung atau \\
ornamen yang \\
menempel pada \\
dinding luar \\
rumah
\end{tabular} & $\begin{array}{l}\text { - Stilisasi bentuk } \\
\text { manusia jongkok }\end{array}$ & $\begin{array}{l}\text { - Pengaruh akal pada hukum } \\
\text { untuk keadilan } \\
\text { - Kebesaran dan kekuatan }\end{array}$ \\
\hline
\end{tabular}

(Sumber: Yudoseputro, 2008; Wijaya, 2013; Marlina, 2017; Siburian, 2018).

Tabel 5. Analisa Semiotika Bahasa Rupa Motif Mimesis Tumbuhan Era Arsitektur Nusantara

\begin{tabular}{|c|c|c|c|c|c|}
\hline \multicolumn{3}{|c|}{ Ikon dan Sintaksis } & \multicolumn{2}{|c|}{ Indeks dan Pragmatik } & \multirow{2}{*}{$\begin{array}{c}\text { Simbol dan Semantik } \\
\text { Makna } \\
\end{array}$} \\
\hline Desain & Posisi (Asal) & Visualisasi/Nama & Fungsi & Karakter Bentuk & \\
\hline 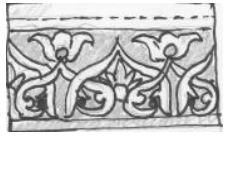 & $\begin{array}{c}\text { Rumah } \\
\text { Gadang } \\
\text { Minang- } \\
\text { kabau }\end{array}$ & Siriah Gadang & $\begin{array}{l}\text { Border bidang } \\
\text { dinding } \\
\text { Ornamen bidang } \\
\text { besar }\end{array}$ & $\begin{array}{l}\text { - Deretan stilisasi } \\
\text { daun sirih, yang } \\
\text { tumbuh bersifat } \\
\text { merambat dan saling } \\
\text { mengikat }\end{array}$ & $\begin{array}{l}\text { - Persatuan adalah yang } \\
\text { utama } \\
\text { - Menjaga persaudaraan dan } \\
\text { rasa sosial } \\
\text { - Dilarang menonjolkan diri }\end{array}$ \\
\hline (2) & $\begin{array}{c}\text { Gorga Batak } \\
\text { (Rumah Adat } \\
\text { Batak) }\end{array}$ & $\begin{array}{l}\text { Pinar Bulung } \\
\text { Andudur } \\
\text { (Merah, Hitam, } \\
\text { Putih) }\end{array}$ & $\begin{array}{l}\text { Hiasan di } \\
\text { samping kiri } \\
\text { kanan pintu } \\
\text { bolon }\end{array}$ & $\begin{array}{l}\text { - Stilisasi daun } \\
\text { andudur/palem sarai } \\
\text { dengan cincin-cincin } \\
\text { ijuk di batang }\end{array}$ & $\begin{array}{l}\text { - Selalu tepat janji } \\
\text { - Selalu memupuk dan } \\
\text { menjalin keakraban }\end{array}$ \\
\hline 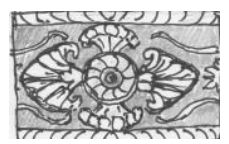 & $\begin{array}{l}\text { Rumah } \\
\text { Banjar }\end{array}$ & $\begin{array}{l}\text { Kambang } \\
\text { Talipuk } \\
\text { (Teratai) }\end{array}$ & $\begin{array}{l}\text { - Border, bidang } \\
\text { panjang } \\
\text { - Hiasan pada } \\
\text { dinding depan }\end{array}$ & $\begin{array}{l}\text { - Stilisasi dari daun } \\
\text { dan bunga teratai } \\
\text { yang tumbuh di } \\
\text { rawa-rawa }\end{array}$ & $\begin{array}{l}\text { - Kesucian } \\
\text { - Kemurnian } \\
\text { - Keselarasan lahir bathin }\end{array}$ \\
\hline
\end{tabular}

(Sumber: Sipayung \& Lingga, 1995; Putra \& Ekomadyo, 2015; Dewi \& Hendrawan, 2016; Amzy, 2017; Marlina, 2017; Aisyah, 2018; Khairuzzaky, 2018).

Tabel-tabel analisis tersebut memperlihatkan bahwa terdapat relasi yang jelas antara visualisasi desain karya rupa yang muncul dalam bermacam-macam wujud motif dan penamaan yang diwujudkan dalam beberapa teknik desain yang akan mengandung pemaknaan sebagai media pemberi pesan adat sesuai rujukannya. Dalam relasi indeks/pragmatik dari karya rupa, terdapat relasinya sebagai fungsi denotatif utama sebagai hiasan rumah adat atau sebagai denotatif pengembangan yang berhubungan dengan penyampaian pesan adat yang bekerja bersamaan.

Oleh karena itu, elemen ragam hias dan ornamen pada rumah adat dipilih posisi penempatannya agar mudah dilihat orang lain sesuai signifikansinya dalam 
menyampaikan pesan adat, seperti pada dinding muka, tiang utama, dan atap rumah. Dengan demikian, pemakaian dan penempatan ornamen pada rumah adat mempunyai fungsi dan makna seperti menunjukkan status sosial, kedekatan dengan alam, dan sebagai tanda terdapatnya pengaruh budaya asing (Macbean, 2013, pp. 4-5; Putra \& Ekomadyo, 2015, pp. 2-3).

Perkembangan historis atau diakronik yang dihubungkan terhadap relasi sistem tanda dapat diwakili oleh skema sebagai berikut.

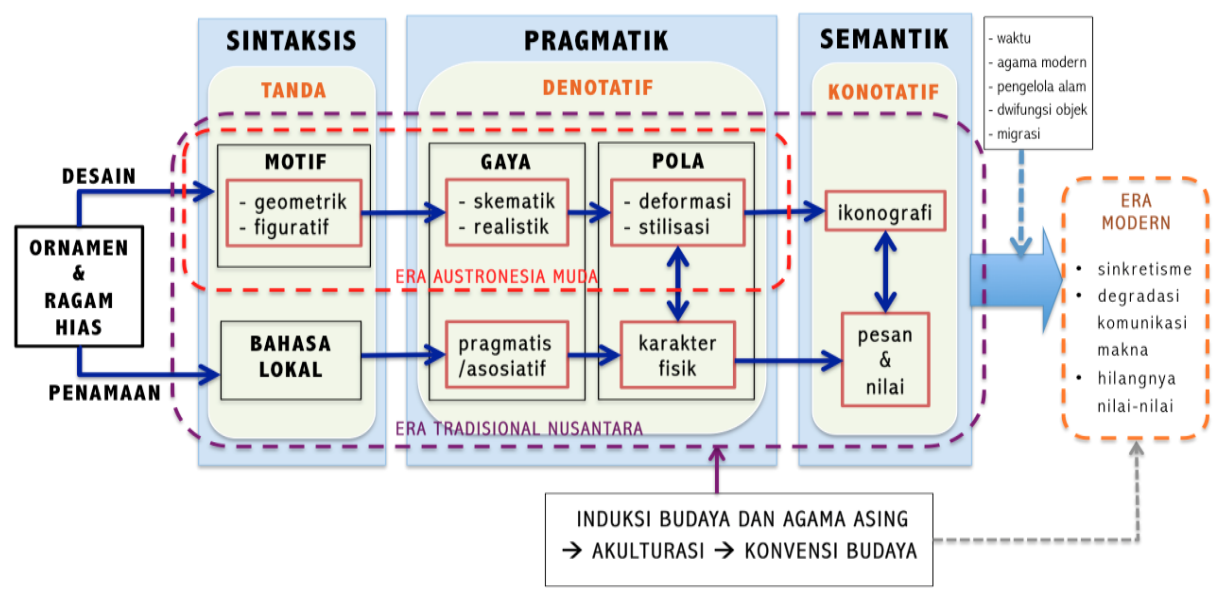

Gambar 8. Analisis Penulis akan Hubungan Antara Sistem Tanda dan Tinjauan Diakronik dari Karya Rupa Ornamen dan Ragam Hias Austronesia-Rumah Adat Nusantara.

Skema ini menunjukkan perkembangan ornamen/ragam hias ini dapat dibagi menjadi tiga era, yaitu (1) Era Austronesia, (2) Era Tradisional Nusantara, dan (3) Era Modern. Secara umum, karya rupa ini adalah ornamen dengan fungsi utama sebagai penghias artifak budaya. Karya rupa ini dapat diurai dalam beberapa motif sebagai tema utama dari kreasi suatu karya seni, yang kemudian akan diturunkan pada beberapa gaya atau tata cara spesifik dalam mengkreasikan karya dan pada tingkat teknik dalam beberapa pola sebagai arahan atau panduan agar tidak menyimpang dari tema utamanya (Kemas, 2017, p. 13).

Pada era Austronesia, karya rupa ini diurai dalam motif geometrik dan figuratif (tumbuhan, hewan, dan manusia) sebagai tema utama karya yang juga berelasi pragmatis dari tanda sebagai ikon dengan instrumen metafora untuk bekerja dalam sintaksisnya. Motif ini kemudian dikreasikan dengan dua macam gaya desain, yaitu gaya skematik (desain konseptual yang memunculkan bentuk unsur-unsur utama) dan gaya realistik (memvisualisasikan sedekat mungkin dengan bentuk asli). Dua gaya ini kemudian diwujudkan dalam teknik visualisasi dengan pola deformasi (merngubah bentuk dasar utamanya) ataupun stilisasi atau penggayaan/melebihkan. Gaya dan pola ini berelasi pragmatis sebagai indeks dan menggunakan instrumen indikasi untuk penggunaan/fungsi/peranannya pada suatu artifak, sedangkan fungsi pengembangan dari karya rupa sebagai bahasa rupa yang berelasi pragmatis pada simbol/semantik tidak dapat dimunculkan, diduga karena tidak ada enskripsi/manuskrip yang menjelaskan. 
Pada zaman kedua di era tradisional Nusantara, eksistensi proses kreasi karya rupa dari motif, gaya, dan pola relatif terjaga pada tahapan seperti di era Austronesia dengan teknik pengerjaan pola desain yang terlihat lebih halus sebagai tanda kemajuan teknologi. Perkembangan yang signifikan dalam proses kreasi yang berelasi dengan ikon/sintaksis adalah adanya penamaan karya rupa lewat bahasa lokal yang pada relasi indeks/pragmatik saling berhubungan dengan cara pandang pragmatis atau asosiatif terhadap motif desain. Dengan demikian, unsur lanjutan dari relasi pragmatik dalam penamaan adalah turunan cara pandang tersebut yang berupa karakter fisik yang menjadi inspirasi desain motifnya. Selanjutnya, era ini juga dipengaruhi oleh faktor eksternal, yaitu masuknya budaya dan agama asing yang membentuk akulturasi yang berlanjut pada suatu konvensi budaya. Karya-karya rupa ini kemudian menyandang sifat sebagai simbol yang dengan instrumen arbitrari sebagai instrumennya yang direlasikan dengan semantik untuk memunculkan makna, pesan, bahkan penjelasan akan lambangnya yang berdampingan dengan nama sebagai tanda yang dibawanya.

Selanjutnya, periode yang ketiga adalah era modern, konvensi budaya satu sudah mulai bercampur dengan yang lainnya. Dalam kondisi ini ornamen/ragam hias sebagai media komunikasi ide dari konsep adat mulai berkurang pengaruhnya dalam memberikan makna dan pesan. Pada era ini juga terdapat sinkretisme akan pemaknaan spiritual karya rupa sebagai bahasa rupa. Hal ini terjadi akibat beberapa hal, antara lain fusi antara teknologi material dan estetika spiritual, manusia sudah mampu mengelola alam untuk kepentingannya, masuknya agama modern (Islam dan Kristen), dan hilangnya takhayul akibat munculnya multifungsi dan makna dari benda-benda yang ada di alam. Pergeseran makna dari simbolisme yang dibawa sebuah karya rupa pada era ini juga berwujud sebagai fungsi dekoratif ketika konsep budaya yang sebagai konteks membaca pesan adat sudah tidak dipakai lagi atau berpindah pada kebudayaan yang lainnya (Vine, 2008, p. 12; Shabalina, 2017, p. 2).

Dari analisis di atas dapat dikemukakan bahwa eksistensi dan perkembangan bahasa rupa dari ornamen dan ragam hias ini masih relatif bertahan sebagai unsur hiasan/fungsi ornamentasinya saja, sedangkan sebagai media komunikasi atau pembawa makna, relatif mengalami penurunan yang disebabkan akulturasi budaya. Di sini dapat juga terlihat adanya potensi peningkatan eksistensi karena dominasi pengembangan sifat indeks/pragmatik dari karya rupa tersebut dapat memunculkan ragam hias/ornamen baru yang tetap berelasi dengan indeks/pragmatik asalnya akan saja tidak berelasi kuat dengan simbol/semantik dari konsep adatnya.

\section{SIMPULAN}

Eksistensi dari perkembangan karya rupa sebagai bahasa rupa memang tidak terlepas dari kerja sama trikotomis antara bentuk/desain, fungsi, serta maknanya beserta relasi-relasi yang ada di dalamnya. Pada arsitektur tradisional Nusantara, adat istiadat memainkan peranan penting agar ornamen dan ragam hias berfungsi sebagai media komunikasi ide dan konsep yang akan membawa karya rupa ini sebagai sistem tanda yang lengkap. Adat istiadat berfungsi sebagai konteks dari pemaknaan/fungsi konotatif 
yang memang pada struktur relasi sistem tanda menempati posisi yang lebih utama dalam sistem tanda. Pengaruh akulturasi budaya dan rentang waktu akan sangat berpengaruh pada perkembangan eksistensi karya rupa ini karena akan dapat menghilangkan konteks yang akan menjadi rujukan dari membaca dan mempersepsikan teks dari makna ornamen dan ragam hias ini. Apabila ini terjadi, perkembangan ornamen/ragam hias yang bersumber dari arsitektur tradisional Nusantara akan terbatas pada eksistensi bernilai denotatum saja walaupun sebagai wujud karya rupa akan terus dapat berkembang. Karena karya rupa ini dalam relasi tanda sebagai indeks akan dapat terus dikembangkan pola desainnya berdasarkan motif dan gaya yang menjadi arahan desain dari ornamen/ragam hias ini tanpa banyak berelasi dengan simbol yang bernilai konotatum.

\section{DAFTAR PUSTAKA}

Aisyah, S. (2018). Pola Dasar Dan Makna Ukiran Motif Rumah Gadang Koto Sani Kecamatan X. Narada, Jurnal Desain \& Seni, 5(3), 401-416. http://publikasi.mercubuana.ac.id/index.php/narada/article/download/2857/2380, https://www.google.com/

Amzy, N. (2017). Analisis makna ornamen rumah gadang dalam perspektif filsafat pendidikan. Jurnal Desain, 04(03), 282-290. https://journal.lppmunindra.ac.id/index.php/Jurnal_Desain/article/viewFile/1465/1 440

Bellwood, P. (2007). Prehistory of the Indo-Malaysian Archipelago (3rd ed.). ANU E Press.

Chiou-Peng, T. (2008). Dian bronze art: its source and formation. Bulletin of the IndoPacific Prehistory Association, 28(0), 34-43. https://doi.org/10.7152/bippa.v28i0.12013

Dewi, N. M. E. N., \& Hendrawan, F. (2016). Kajian Semiotika Ornamen dan Dekorasi Interior Kelenteng Sebagai Wujud Inkulturasi Budaya di Kota Denpasar. Seminar Nasional Tradisi Dalam Perubahan: Arsitektur Lokal Dan Rancangan Lingkungan Terbangun - Bali 2016, 1-14.

Eco, U. (1980). Function and Sign: The Semiotics of Architecture. In G. Broadbent, R. Bunt, \& C. Jencks (Eds.), Signs, Symbols, and Architecture (pp. 11-69). John Wiley \& Sons.

Fox, J. J. (2006a). Austronesian Societies and Their Transformations. In P. Bellwood, J. J. Fox, \& D. Tyron (Eds.), The Austronesians: Historical and Comparative Perspectives. (pp. 229-244). ANU E Press.

Fox, J. J. (2006b). Comparative Perspectives on Austronesian Houses: An Introductory Essay. In J. J. Fox (Ed.), Inside Austronesian Houses, Perspective on Domestic Designs for Living (pp. 1-29). ANU E Press.

Groves, C. P. (2006). Domesticated and Commensal Mammals of Austronesia and Their Histories. In P. Bellwood, J. J. Fox, \& D. Tyron (Eds.), The Austronesians, Historical and Comparative Perspectives (pp. 161-174). ANU E Press. 
Hidayat, H. N. (2018). Pengembangan Motif Ukiran Rumah Gadang untuk Motif Kain: Revitalisasi dan Pengembangan Industri Kreatif. Jurnal Ilmiah Lingua Idea, 9(1), $11-22$.

Hoed, B. H. (2014). Semiotik \& Dinamika Sosial Budaya (3rd ed.). Komunitas Bambu.

Jencks, C. (1980). The Architectural Sign. In G. Broadbent, R. Bunt, \& C. Jencks (Eds.), Signs, Symbols, and Architecture (pp. 72-118). John Wiley \& Sons.

Jusoh, A. (2016). Kebudayaan Dongson di Asia Tenggara: Satu Tafsiran Berdasarkan Penemuan Arkeologi. Purba -Jurnal Persatuan Muzium Malaysia, 35, 1-28.

Kemas, W. P. (2017). Analisis Semiotika pada Ornamen Masjid Jamik Ismaliyah Serdang Bedagai [Universitas Sumatera Utara].

http://repositori.usu.ac.id/bitstream/handle/123456789/1974/130704029.pdf?seque nce $=1 \&$ isAllowed $=\mathrm{y}$

Khairuzzaky, K. (2018). Kajian Struktur Ragam Hias Ukiran Tradisional Minangkabau Pada Istano Basa Paguruyung. Jurnal Titik Imaji, 1(1), 54-67. https://doi.org/10.30813/.v1i1.1090

Kharisma, A., Amiuza, C. B., \& Ridjal, A. M. (2015). Semantik Arsitektur Pada Pasar Seni Kabupaten Sidoarjo. Jurnal Mahasiswa Jurusan Arsitektur, 3(1). http://arsitektur.studentjournal.ub.ac.id/index.php/jma/article/view/95

Leihitu, I., \& Permana, R. C. E. (2019). A Reflection of Painting Tradition and Culture of the Austronesian Based on the Rock Art in Misool, Raja Ampat, West Papua. Journal of Southeast Asian Studies, 24(1), 220-242. https://doi.org/10.22452/jati.vol24no1.9

Lullulangi, M., \& Sampebua', O. (2007). Arsitektur Tradisional Toraja. Badan Penerbit Universitas Negeri Makassar.

Macbean, A. C. (2013). Art and Symbolism The Technique of Applying Hidden Meaning and Communicating Specific Ideas Through Art [Liberty University]. https://digitalcommons.liberty.edu/cgi/viewcontent.cgi?article=1414\&context=hon ors

Mallabasa, Y., \& Subiantoro, B. (2018). Sejarah Seni Rupa Indonesia: Bagian I: Prasejarah. Program Studi Pendidikan Seni Rupa, Universitas Negeri Makassar. https://www.academia.edu/39644329/Sejarah_Seni_Rupa_Indonesia_Prasejarah

Marlina, H. (2017). Kajian Semiotik Motif Pakaian Adat Suku Dayak Kenyah di Desa Pampang Samarinda Kalimantan Timur. Jurnal Jurusan Seni Murni ISI Yogyakarta. http://digilib.isi.ac.id/1360/6/Jurnal Kajian Semiotika Motif pakaian Adat Dayak Kenyah Herlinda Marlina.pdf

Mayasari, M. S., Tulistyantoro, L., \& Rizqy, M. T. (2014). Kajian Semiotik Ornamen Interior Pada Lamin Dayak Kenyah (Studi Kasus Interior Lamin di Desa Budaya Pampang). Jurnal Intra, 2(2), 288-293.

https://media.neliti.com/media/publications/94495-ID-kajian-semiotik-

Maziyah, S., Mahirta, M., \& Atmosudiro, S. (2016). Makna Simbolis Batik Pada Masyarakat Jawa Kuna. Paramita: Historical Studies Journal, 26(1), 23-32. https://doi.org/10.15294/paramita.v26i1.5143 
Prasetya, L. E., \& Adi, S. M. (2011). Makna dan Filosofi Ragam Hias Pada Rumah Tradisional Minangkabau di Nagari Pariangan Tanah Datar. Prosiding Seminar Nasional "Kearifan Lokal Dalam Keberagaman Untuk Pembangunan Indonesia", 2001, 59-70.

Prasetyo, F. A. (2014). Cosmology of Nias Architecture. In U. Jogjakarta (Ed.), Seminar Nasional Arsitektur Merah Putih, Ruang \& Tempat dalam Latar Indonesia (Issue July, pp. 1-16). UKDW Yogyakarta.

Putra, R. A., \& Ekomadyo, A. S. (2015). Penguraian Tanda (Decoding) pada Rumah Aceh dengan Pendekatan Semiotika (Elaboration of Sign (Decoding) of Rumoh Aceh Using Semiotics Approach). Tesa Arsitektur, Journal of Architectural Discourses, 13(1), 1-14. https://doi.org/10.24167/TESA.V13I1.354

Sachari, A. (2005). Metodologi Penelitian Budaya Rupa (W. Hardani (ed.); 1st ed.). Erlangga.

Shabalina, N. M. (2017). Design and Decorative Art in Shaping of Architectural Environment Image. IOP Conference Series: Materials Science and Engineering, 262(1), 1-6. https://doi.org/10.1088/1757-899X/262/1/012137

Siburian, D. E. (2018). Pengenalan Motif Gorga Singa-singa. Jurnal ATRAT, 6(1), 112.

Sipayung, H., \& Lingga, A. (1995). Ragam Hias (Ornamen) Rumah Tradisional Simalungun (S. Purba (ed.)). Museum Neg. Prop. Sumatera Utara.

Solheim II, W. G. (1990). A Brief History of the Dongson Concept. In Asian Perspectives (Vol. 28, Issue 1).

Thomas, D. R. (2011). Origins of the Austronesian Peoples. In N. A. Rahman, Z. Ramli, M. Musa, \& A. Jusoh (Eds.), Alam Melayu: Satu Pengenalan (Malay World: One Contribution to Knowledge) (pp. 13-21). Institut Alam dan Tamandun Melayu, Universiti Kebangsaan Malaysia.

van Heekeren, H. R. (1958). The Bronze-Iron Age of Indonesia. Nijhoff. https://doi.org/10.1163/9789004286443

Viaro, A. (2008). Nias Island traditional houses. In R. Schefold, P. J. Nas, G. Domenig, \& R. Wessing (Eds.), Indonesian Houses (pp. 175-235). Brill. https://doi.org/10.1163/9789004253988_008

Vine, S. A. (2008). Visual Forms and Symbolism in Traditional South Asian ArtChanges in Art Making, the Importance of Urban Folk Art. Lahore University.

Waterson, R. (2006). Houses and the Built Environment in Island South-East Asia: Tracing some shared themes in the uses of space. In J. J. Fox (Ed.), Inside Austronesian Houses, Perspective on Domestic Designs for Living (pp. 227-242). ANU E Press.

Wijaya, H. (2013). Nekara: Peninggalan Seni Budaya Dari Zaman Perunggu.

Humaniora, 4(1), 212-220.

https://journal.binus.ac.id/index.php/Humaniora/article/download/3431/2817 